\title{
Evidence for Upwelling of Corrosive "Acidified" Water onto the Continental Shelf
}

Richard A. Feely, ${ }^{1 *}$ Christopher L. Sabine, ${ }^{1}$ J. Martin Hernandez-Ayon, ${ }^{2}$ Debby Ianson, ${ }^{3}$ Burke Hales ${ }^{4}$

${ }^{1}$ Pacific Marine Environmental Laboratory/NOAA, 7600 Sand Point Way NE, Seattle, WA 98115-6349, USA. ${ }^{2}$ Instituto de Investigaciones Oceanologicas. Universidad Autonoma de Baja California. Km. 103 Carr. Tijuana-Ensenada. Ensenada. Baja California. Mexico. ${ }^{3}$ Fisheries and Oceans Canada, Institute of Ocean Science, P.O. Box 6000, Sidney, BC V8L 4B2, Canada. ${ }^{4}$ College of Oceanic and Atmospheric Sciences, Oregon State University, 104 Ocean Admin. Bldg., Corvallis, OR 97331-5503, USA.

*To whom correspondence should be addressed. E-mail: richard.a.feely@noaa.gov

The absorption of atmospheric carbon dioxide into the ocean lowers the $\mathrm{pH}$ of the waters. This so-called ocean acidification could have important consequences for marine ecosystems. In order to better understand the extent of this ocean acidification in coastal waters, we conducted hydrographic surveys from central Canada to northern Mexico. We observed seawater that is undersaturated with respect to aragonite upwelling onto large portions of the continental shelf, reaching depths of approximately 40-120 m along most transect lines and all the way to the surface on one transect off northern California. While seasonal upwelling of the undersaturated waters onto the shelf is a natural phenomenon in this region, the ocean uptake of anthropogenic $\mathrm{CO}_{2}$ has increased the areal extent of the affected area.

Over the past 250 years the release of carbon dioxide $\left(\mathrm{CO}_{2}\right)$ from industrial and agricultural activities has resulted in atmospheric $\mathrm{CO}_{2}$ concentrations that have increased by about 100 parts per million (ppm). The atmospheric concentration of $\mathrm{CO}_{2}$ is now higher than it has been for at least the last 650,000 years, and is expected to continue to rise at an increasing rate, leading to significant changes in our climate by the end of this century (1). Since the beginning of the industrial era, the oceans have absorbed approximately $127 \pm$ 18 billion metric tons of carbon as carbon dioxide from the atmosphere, or about one third of the anthropogenic carbon emissions released (2). This process of absorption of anthropogenic $\mathrm{CO}_{2}$ has benefited humankind by significantly reducing the greenhouse gas levels in the atmosphere and minimizing some of the impacts of global warming. However, the ocean's daily uptake of 30 million metric tons of carbon dioxide is significantly impacting its chemistry and biology. Recent hydrographic surveys and modeling studies have confirmed that the uptake of anthropogenic $\mathrm{CO}_{2}$ by the oceans has resulted in a lowering of seawater $\mathrm{pH}$ by about 0.1 since the beginning of the industrial revolution (3-7). This phenomenon, which is commonly called "ocean acidification," could affect some of the most fundamental biological and geochemical processes of the sea in the coming decades and could seriously alter the fundamental structure of pelagic and benthic ecosystems ( 8 ).

Estimates of future atmospheric and oceanic carbon dioxide concentrations, based on the Intergovernmental Panel on Climate Change (IPCC) $\mathrm{CO}_{2}$ emission scenarios and general circulation models, indicate that atmospheric carbon dioxide levels could exceed 500 parts per million (ppm) by the middle of this century, and $800 \mathrm{ppm}$ near the end of the century. This increase would result in a surface water $\mathrm{pH}$ decrease of approximately $0.4 \mathrm{pH}$ units, and a corresponding $50 \%$ decrease in carbonate ion concentration by the end of the century $(5,9)$. Such rapid changes are likely to negatively impact marine ecosystems, seriously jeopardizing the multifaceted economies that currently depend on them (10).

The reaction of $\mathrm{CO}_{2}$ with seawater reduces the availability of carbonate ions that are necessary for calcium carbonate $\left(\mathrm{CaCO}_{3}\right)$ skeleton and shell formation for a number of marine organisms such as corals, marine plankton, and shellfish. The extent to which the organisms are affected is largely dependent upon the calcium carbonate $\left(\mathrm{CaCO}_{3}\right)$ saturation state $(\Omega)$, which is the product of the concentrations of $\mathrm{Ca}^{2+}$ and $\mathrm{CO}_{3}{ }^{2-}$ divided by the apparent stoichiometric solubility product for either aragonite or calcite:

$$
\begin{aligned}
\Omega \text { arag } & =\left[\mathrm{Ca}^{+2}\right]\left[\mathrm{CO}_{3}^{-2}\right] / \mathrm{K}^{\prime} \mathrm{sp}_{\text {arag }} \\
\Omega \mathrm{cal} & =\left[\mathrm{Ca}^{+2}\right]\left[\mathrm{CO}_{3}^{-2}\right] / \mathrm{K}^{\prime} \mathrm{sp}_{\text {cal }}
\end{aligned}
$$

where the calcium concentration is estimated from the salinity, and the carbonate ion concentration is calculated from the dissolved inorganic carbon (DIC) and total alkalinity (TA) measurements (11). In regions where $\Omega$ arag or $\Omega \mathrm{cal}$ is $>$ 1.0 the formation of shells and skeletons is favored. Below a value of 1.0 the water is corrosive and dissolution of pure aragonite and unprotected aragonite shells will begin to occur (12). Recent studies have demonstrated that in many regions of the ocean the aragonite saturation horizon shoaled as much 
as 40-200 $\mathrm{m}$ as a direct consequence of the uptake of anthropogenic $\mathrm{CO}_{2}(3,5,6)$. It is shallowest in the northeastern Pacific Ocean, only 100-300 m from the ocean surface, allowing for the transport of undersaturated waters onto the continental shelf during periods of upwelling.

In May and June of 2007, we conducted a North American Carbon Program (NACP) West Coast Cruise on the Research Ship Wecoma along the continental shelf of western North America, completing a series of 13 cross-shelf transects from Queen Charlotte Sound, Canada to San Gregorio Baja California Sur, Mexico (Fig. 1). Full water column conductivity-temperature-depth-rosette (CTDR) stations were occupied at specified locations along each transect (Fig. 1). Water samples were collected in modified Niskin-type bottles and analyzed for DIC, TA, oxygen, nutrients and dissolved and particulate organic carbon. Aragonite and calcite saturation, $\mathrm{pH}_{S W}$, and $p \mathrm{CO}_{2}$ were calculated from the DIC and TA data (11).

The central and southern coastal region off western North America is strongly influenced by seasonal upwelling which typically begins in early spring when the Aleutian low pressure system moves to the northwest and the Pacific High moves northward, resulting in a strengthening of the northwesterly winds $(13,14)$. These winds drive net surface water Ekman transport offshore, which induces the upwelling of $\mathrm{CO}_{2}$-rich intermediate depth (100-200 m) offshore waters onto the continental shelf. The upwelling lasts until late summer or fall when winter storms return.

During the cruise, various stages and strengths of upwelling were observed from line 2 off central Vancouver Island to line 11 off Baja California, Mexico. We observed recent upwelling on lines 5 and 6 near the Oregon-California border. Coincident with the upwelled waters, we found evidence for undersaturated, low $\mathrm{pH}$ seawater in the bottom waters as depicted by $\Omega$ arag values $<1.0$ and $\mathrm{pH}$ values $<$ 7.75. The corrosive waters reached mid-shelf depths of approximately 40-120 $\mathrm{m}$ along lines 2-4, and 7-13 (Fig. 1). In the region of the strongest upwelling (line 5), the isolines of $\Omega$ arag $=1.0, \mathrm{DIC}=2190$ and $\mathrm{pH}=7.75$ closely followed the 26.2 potential density surface (Fig. 2). This density surface shoaled from a depth of $\sim 150 \mathrm{~m}$ in the offshore waters and breached the surface over the shelf near the $100 \mathrm{~m}$ bottom contour, approximately $40 \mathrm{~km}$ from the coast. This shoaling of the density surfaces and $\mathrm{CO}_{2}$-rich waters as one approaches land is typical of strong coastal upwelling conditions (15-18). The surface water $\mathrm{pCO}_{2}$ on the 26.2 potential density surface was about $850 \mu \mathrm{atm}$ near the shelfbreak and higher inshore (Fig. 2), possibly enhanced by respiration processes on the shelf (17). These results indicate that the upwelling process caused the entire water column shoreward of the $50 \mathrm{~m}$ bottom contour to become undersaturated with respect to aragonite, a condition that was not predicted to occur in open-ocean surface waters until 2050 (5). On line 6, the next transect south, the undersaturated water was close to the surface at approximately $22 \mathrm{~km}$ from the coast. The lowest $\Omega$ arag values $(<0.60)$ observed in the near-bottom waters of the continental shelf corresponded with $\mathrm{pH}$ values close to 7.5. Since the calcite saturation horizon is located between 225 $400 \mathrm{~m}$ in this part of the northeastern Pacific (19), it is still too deep to shoal onto the continental shelf. Nevertheless, the calcite saturations values drop in the core of the upwelled water $(\Omega \mathrm{cal}<1.3)$.

As noted, the North Pacific aragonite saturation horizons are among the shallowest in the global ocean (3). The uptake of anthropogenic $\mathrm{CO}_{2}$ has caused these horizons to shoal by 50-100 m since pre-industrial times so that they are within the density layers that are currently being upwelled along the west coast of North America. Although much of the corrosive character of these waters is the natural result of respiration processes at intermediate depths below the euphotic zone, this region continues to accumulate more anthropogenic $\mathrm{CO}_{2}$ and, therefore, the upwelling processes will expose coastal organisms living in the water column or at the seafloor to less saturated waters exacerbating the biological impacts of ocean acidification.

Based on our observed $\mathrm{O}_{2}$ values and estimated $\mathrm{O}_{2}$ consumption rates on the same density surfaces (20), the upwelled water off northern California (line 5) was last at the surface about 50 years ago when atmospheric $\mathrm{CO}_{2}$ was about 65 ppm lower than today. The open ocean anthropogenic $\mathrm{CO}_{2}$ distributions in the Pacific have been estimated previously $(19,4,21)$. By determining the density-dependence of anthropogenic $\mathrm{CO}_{2}$ distributions in the eastern-most North Pacific stations of the Sabine et al (21) data set, we estimate that these upwelled waters contain approximately $31 \pm 4$ umol kg-1 anthropogenic $\mathrm{CO}_{2}$ (fig. S2). Removing this signal from the DIC increases the aragonite saturation state of the waters by about 0.2 units. Thus, without the anthropogenic signal, the equilibrium aragonite saturation level $(\Omega$ arag $=1)$ would be deeper by about $50 \mathrm{~m}$ across the shelf, and no undersaturated waters would reach the surface. Water already in transit to upwelling centers is carrying increasing anthropogenic $\mathrm{CO}_{2}$ and more corrosive conditions to the coastal oceans of the future. Thus the undersaturated waters, which were mostly a problem for benthic communities in the deeper waters near the shelf break in the pre-industrial era, have shoaled closer to the surface and near the coast because of the additional inputs of anthropogenic $\mathrm{CO}_{2}$.

These observations clearly show that seasonal upwelling processes enhance the advancement of the corrosive deep water into broad regions of the North American western continental shelf. Since the region experiences seasonal periods of enhanced aragonite undersaturation, it is important to understand how the indigenous organisms deal with this 
exposure and whether or not future increases in the range and intensity of the corrosiveness will affect their survivorship. Presently, little is known about how this intermittent exposure to corrosive water might impact the development of larval, juvenile and adult stages of aragonitic calcifying organisms or finfish that populate the neritic and benthic environments in this region and fuel a thriving economy. Laboratory and mesocosm experiments show that these changes in saturation state may cause significant changes in overall calcification rates for many species of marine calcifiers including corals, coccolithophores, foraminifera and pteropods, which are a significant food source for local juvenile salmon $(8,22-30)$. Similar decreases in calcification rates would be expected for edible mussels, clams and oysters $(22,31)$. Other research indicates that many species of juvenile fish and shellfish of significant economic importance to coastal regions are highly sensitive to higher-than-normal $\mathrm{CO}_{2}$ levels such that high rates of mortality are directly correlated with the higher $\mathrm{CO}_{2}$ levels $(31,32)$. While comprehensive field studies of organisms and their response to sporadic increases in $\mathrm{CO}_{2}$ along the western North American coast are lacking, current studies suggest that further research under field conditions is warranted. Our results show for the first time that a large section of the North American continental shelf is impacted by ocean acidification. Other continental shelf regions may also be impacted where anthropogenic $\mathrm{CO}_{2}$-enriched water is being upwelled onto the shelf.

\section{References and Notes}

1. U. Siegenthaler et al., Science 310, 1313 (2005).

2. C. L. Sabine, R. A. Feely, in Greenhouse Gas Sinks, D. Reay, N. Hewitt, J. Grace, K. Smith, Eds. CABI Publishing, Oxfordshire, UK (2007).

3. R. A. Feely et al., Science 305, 362 (2004).

4. C. L. Sabine et al., Science 305, 367 (2004).

5. J. C. Orr et al., Nature 437, 681 (2005).

6. K. Caldeira, M. E. Wickett, Journal Of Geophysical Research-Oceans 110 (2005).

7. R. A. Feely et al., PICES Press 16(1), 22 (2008).

8. J. A. Kleypas et al., Impacts of Increasing Ocean Acidification on Coral Reefs and Other Marine Calcifiers: A Guide for Future Research, report of a workshop held 18-20 April 2005, St. Petersburg, FL (2006), pp. 90.

9. Solomon, S. et al., Eds, in Contribution of Working Group I to the Fourth Assessment Report of the Intergovernmental Panel on Climate Change, Cambridge Univ. Press, Cambridge, UK, and New York (2007).

10. Royal Society, "Ocean acidification due to increasing atmospheric carbon dioxide" (The Royal Society, 2005).

11.The details of the analytical methods and calculations for the carbonate system and anthropogenic $\mathrm{CO}_{2}$ are given in the supporting online material.

12.R. A. Feely et al., Mar. Chem. 25, 227-241 (1988).
13. B. Hickey, in The Sea A. R. Robinson, K. H. Brink, Eds. (John Wiley and Sons, Inc., vol. II. (1998).

14. J. T. Pennington, F. P. Chavez, Deep-Sea Res. II 47, 947 (2000).

15.A. van Geen et al., Deep-Sea Res. Part II 47, 975-1002 (2000).

16. G. E. Friederich, P. M. Walz, M. G. Burczynski, F. P. Chavez, Progress in Oceanography 54, 185 (2002).

17.D. Ianson et al., Deep-Sea Res. Part I, 50, 1023-1042 (2003).

18.B. Hales et al., Global Biogeochemical Cycles 19, doi: 10.1029/2004GB002295 (2005).

19. R. A. Feely et al., Global Biogeochemical Cycles 16, art. no. 1144 (2002).

20. R. A. Feely et al., J. of Oceanography 60(1), 45-52 (2004).

21.C.L. Sabine et al., Global Biogeochem. Cycles 16, 4, 1083, doi: 10.1029/2001GB001639 (2002).

22. M. A. Green, M. E. Jones, C. L. Boudreau, R. L. Moore, B. A. Westman, Limnology And Oceanography 49, 727 (2004).

23. J. M. Guinotte et al., Coral Reefs 22, 551 (2003).

24. C. Langdon, M. J. Atkinson, Journal Of Geophysical Research-Oceans 110, art. no. C09S07 (2005).

25. H. J. Spero et al., Nature 390, 497 (1997).

26. U. Riebesell et al., Nature 407, 364 (2000).

27. I. Zondervan et al., Global Biogeochemical Cycles 15, 507 (2001).

28. B. A. Seibel, V. J. Fabry, Advances in Applied Biodiversity Science 4, 59 (2003).

29. B. Delille et al., Global Biogeochemical Cycles 19, GB2023 (2005).

30. A. Engel et al., Limnology and Oceanography 50, 493 (2005).

31. F. Gazeau et al., Geophys Res Lett. 34, L07603, doi:10.1029/2006GL028554. (2007).

32. A. Ishimatsu et al., Journal of Oceanography 60, 731 (2004).

33. We thank Captain Richard Verlini and the crew of the $R / V$ Wecoma for logistics support. We also thank Dana Greeley, David Wisegarver, Paul Covert, and Sylvia Barry for the DIC and TA measurements. Financial support for this work was provided by the National Oceanic and Atmospheric Administration's Global Carbon Cycle Program and the National Aeronautical and Space Administration Ocean Biology and Biogeochemistry Program.

\section{Supporting Online Material}

www.sciencemag.org/cgi/content/full/1155676/DC1

Materials and Methods

Figs. S1 and S2 


\section{References}

25 January 2008; accepted 13 May 2008

Published online 22 May 2008; 10.1126/science. 1155676

Include this information when citing this paper.

Fig. 1. Distribution of the depths of the undersaturated water (aragonite saturation $<1.0 ; \mathrm{pH}<7.75$ ) on the continental shelf of western North America from Queen Charlotte Sound, Canada to San Gregorio Baja California Sur, Mexico. On transect lines 5 the corrosive water reaches all the way to the surface in the inshore waters near the coast. The black dots represent station locations.

Fig. 2. Vertical sections of: (A) temperature, (B) aragonite saturation, (C) $\mathrm{pH},(\mathbf{D}) \mathrm{DIC}$ and $(\mathbf{E}) p \mathrm{CO}_{2}$, on transect line 5 off Pt. St. George, California. Note that the potential density surfaces are superimposed on the temperature section. The 26.2 potential density surface delineates the location of the first instance of the undersaturated water being upwelled from depths of 150-200 m onto the shelf and outcropping at the surface near the coast. The black dots represent sample locations. 


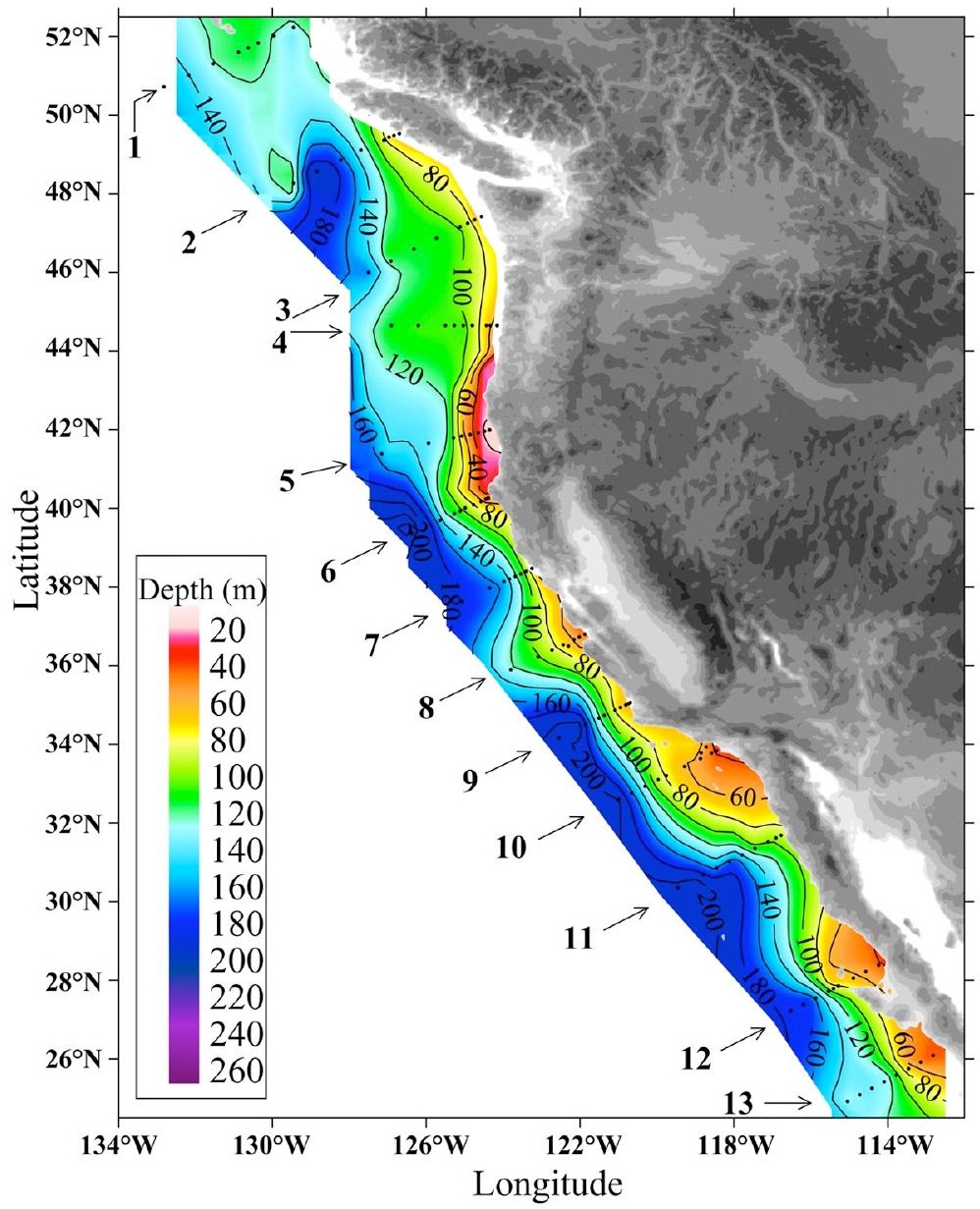




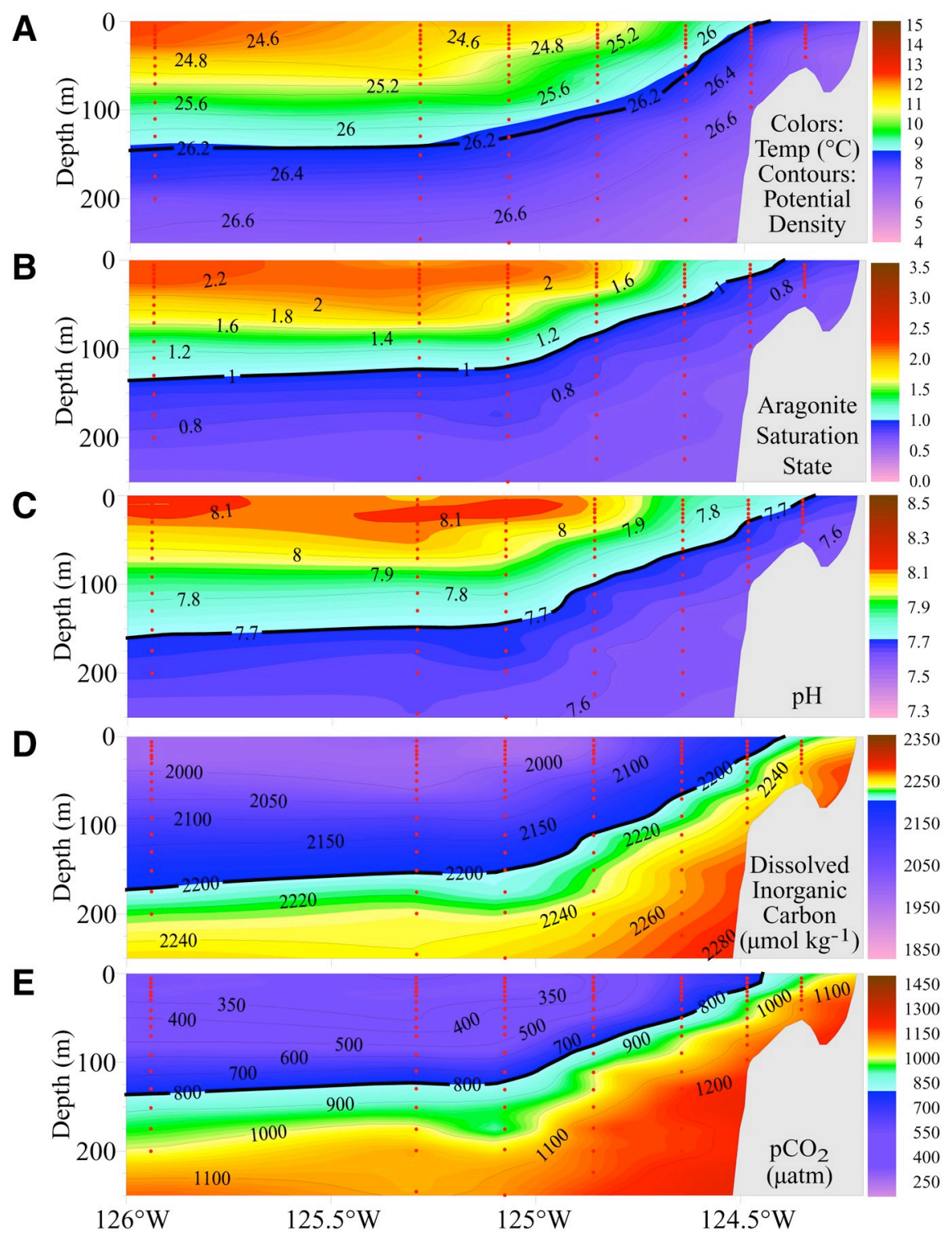

